\title{
An Adaptive Maintenance Model Oriented to Process Environment of the Manufacturing Systems
}

\author{
Xun Gong, ${ }^{1,2}$ Yixiong Feng, ${ }^{1}$ Hao Zheng, ${ }^{1}$ and Jianrong Tan ${ }^{1}$ \\ ${ }^{1}$ State Key Lab of Fluid Power Transmission and Control, Zhejiang University, Hangzhou 310027, China \\ ${ }^{2}$ Robotics and Microsystems Center, Soochow University, Suzhou 215006, China \\ Correspondence should be addressed to Yixiong Feng; fyxtv@zju.edu.cn
}

Received 29 April 2014; Revised 28 May 2014; Accepted 30 May 2014; Published 29 June 2014

Academic Editor: Xuefeng Chen

Copyright (c) 2014 Xun Gong et al. This is an open access article distributed under the Creative Commons Attribution License, which permits unrestricted use, distribution, and reproduction in any medium, provided the original work is properly cited.

\begin{abstract}
We explored an adaptive maintenance model of the process environment to diagnose progressive faults in manufacturing systems. Progressive faults are usually caused by deterioration of the operating environment or aging and show stochastic properties. Many researchers have reported how to detect faults on the machine body in manufacturing systems. However, little research has been conducted on the process environment which causes progressive faults. To tackle this problem, we explored an adaptive maintenance model to detect progressive faults and repair the process environment on the E-repair location. When a difference of the environmental factor state is detected, it will combine the transcription factor and the state enzyme to locate fault source. Then the comprehensive maintenance program is derived to repair the operating environment while eliminating progressive faults. For the purpose of validation, this model was implemented on the process environment of the air separation plant. And the simulation experiments validated the feasibility and effectiveness of this method.
\end{abstract}

\section{Introduction}

Some large complex manufacturing systems are often operated under high pressures, at high temperatures, with fast material flows and complex manufacturing mechanism. In production, facility malfunction, environmental fluctuation, or feed stream instability can introduce a variety of process disturbances, which would aggravate the load of the equipment, accelerate wear and tear on the components, and increase the consumption of electricity or power. Severe combined disturbance propagations in a plant can be destructive. Obviously, such security threatening situations should be detected early, the potential impact on production should be precisely monitored, and operational solutions should be derived quickly.

Failure process in practical engineering applications mainly includes fault diagnosis and maintenance. Publishing of Beard's doctoral dissertation in 1971 marked the birth of fault diagnosis technology [1]. Since then, the fault diagnosis technology has become a research focus and scholars have conducted extensive and in-depth researchin two groups: (1) the model-based methods: some intelligent classification algorithms, such as artificial neural networks (ANNs) and support vector machines (SVM), have been successfully used for fault diagnosis of mechanical systems [2-5]. In machine condition monitoring and fault diagnosis, some researchers have used this as a tool for classification of faults $[6,7] ;(2)$ the data-driven methods: this group of methods monitored and collected the input and output signals of the manufacturing process [8-11]. It extracted fault features from a large number of practical samples, described the relationships between faults and symptoms, and then constructed deep knowledge of expert systems $[12,13]$.

The concept of preventive maintenance (PM) involves the performance of maintenance activities prior to the failure of equipment $[14,15]$. One of the main objectives of PM is to reduce the failure rate or failure frequency of the equipment. This strategy contributes to minimizing failure costs and machine downtime (production loss) and increasing product quality [16]. Reliability-centered maintenance emphasizes on equipment reliability and the consequences of equipment failure as the main basis for maintenance strategy $[17,18]$; fault limited strategy decides whether to maintain the system or not by the failure rate and reliability as indicators [19]; 
condition-based maintenance strategies are monitoring the system [20, 21]; engineering systems maintenance strategy mainly considers the economic relations among the system devices [22].

The studies of environmental factors that affect product performance have focused on environmental simulation test before the operational process [23]. These methods exposed the defects of product components by the reliability enhancement testing. The adaptability of product was improved according to the scheduled test environment. The existing fault diagnosis and maintenance techniques are mostly oriented to device components or the system itself but not deep enough to the environmental factors stress which causes the failure [24].

From the year of failure statistics of the US airborne electronic equipment [25], it can be found that the fault caused by the temperature accounted for $22.2 \%$; by the vibration accounted for $11.38 \%$; by moisture accounted for $10 \%$; by the dust accounted for $4.16 \%$; by the salt spray accounted for $1.94 \%$; by the impact accounted for $1.11 \%$; by other causes accounted for $47.3 \%$. From the above statistics it can be seen that the $52 \%$ of the total fault of the equipment system failures is caused by environmental stress factors of temperature, vibration, humidity, and pollution. At the same time the environmental stress factors also affect the validity of the detection data, thereby affecting the accuracy of fault diagnosis and blocking the maintenance work.

Motivated by those problems, we want to propose a maintenance method of the process environment to bridge the gap. The paper is presented as follows. Section 1 reviews briefly the development of the diagnosis and the maintenance. Section 2 presents the prerequisites of the method by analyzing the fundamental of the environmental stress response. Section 3 proposes the adaptive maintenance model to repair the abnormal process environment to be normal. Section 4 analyzes the temperature sensitivity of the air separation process (the precooling system/purification system/booster expansion turbine/refrigeration system). Section 5 presents the experiments on the air separation plant to test the feasibility and effectiveness of the adaptive maintenance model. Section 6 highlights findings of the paper and suggests potential research directions.

\section{Prerequisite}

Environmental stress response is defined as follows: during the P-F interval in the operating environment, it monitors the environmental factors of the equipment/system (the time from the potential failure to functional failure of the equipment called P-F interval). Once the early warning is in the potential failure state, the equipment/system is diagnosed timely to find out the disturbance source of the environmental factors. The operating environment is maintained in real time on the environmental repair location to avoid the duration of the potential failure state and the functional failure. It is shown in Figure 1.

By the above description of the fundamental of the environmental stress response and Figure 1, it can be seen that the presence, occurrence, diagnosis, and maintenance of

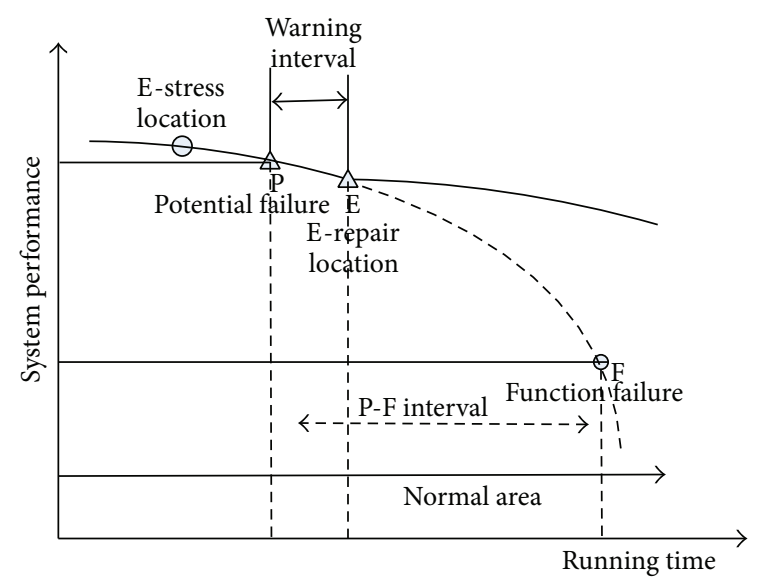

FIGURE 1: System performance of environmental stress response.

the operating environment potential failure have their own prerequisites. The adaptive maintenance model of the equipment/system operating environment in this paper requires some prerequisites like the following:

(1) a certain degree of fault sensitivity to environmental stress;

(2) determining an obvious potential failure state P;

(3) less than P-F interval time length of fault warning and carrying out the environmental stress response at the environmental restoration point E;

(4) the minimum P-F interval which must be long enough to arrange prevention and the environmental stress response in the potential failure process, but not the functional failure process.

The failure cumulative effect of the system is caused by environmental stress and it declines the system performance seriously. Various preventive techniques are used to diagnose potential failure timely to avoid the occurrence of functional failure. The environmental stress response on the environmental repair location repairs the operating failure environment to normal, to extend the lifetime of the system.

\section{Methodology}

3.1. Diagnostic Description. The mechanical device is constituted by the function, behavior, structure, carriers, and other design elements. In the mechanical system design theory, there are reciprocating mapping relationships among function domain, behavior domain, and carrier domain [26]. During operation, the device performance degrades because of fluctuations in E-factors. As shown in Figure 2, in order to diagnose the potential fault of the operating environment of the equipment in an abnormal operating environment, environment domain, monitoring domain, and state domain are increased beside equipment design elements domains.

Environmental domain is the set of E-factors in the equipment operating condition. The real-time state of the operating environment is gathered by monitoring the Efactors timely. The state data is traced back to the source of fluctuations in E-factors by diagnosing and analyzing. 


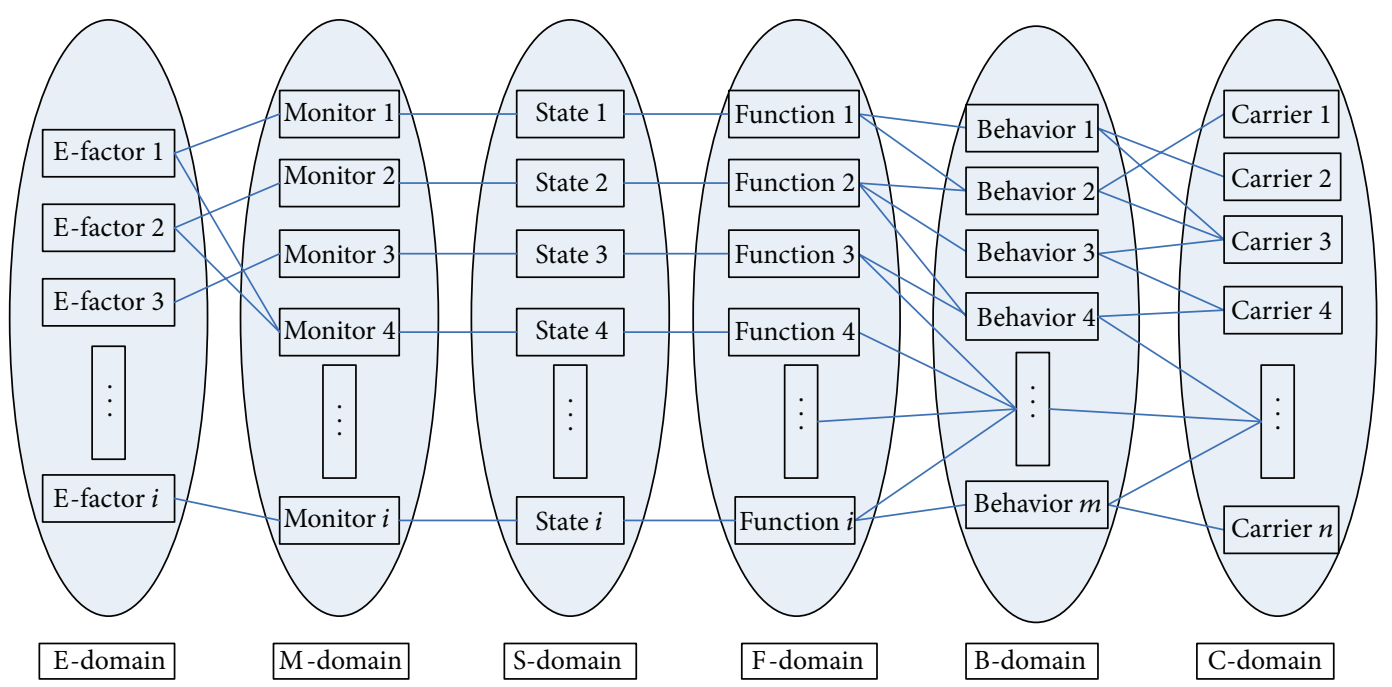

FIGURE 2: Domain structure mapping model.

The temperature is one of the E-factors which the equipment must face. Its fluctuations affect the performance of the system. For example, high temperature could cause thermal aging, structure changing, or physical expansion, while low temperature could cause material physical contraction, and temperature changes could cause the expansion and contraction, the institution stress, and so on.

Humidity is another E-factor. The high humidity stress can cause moisture accumulation and electrochemical reaction resulting in potential failures, while the low humidity stress can cause materials dried, grain, or other reactions.

The E-factors are various and random in reality, and there are mutual interactions among them. There are other E-factors leading to the system failure such as vibration/pressure/salt spray.

3.2. Adaptive Maintenance Model. The environment of the factory in which the equipment locates is extremely complex. There are a variety of disturbance sources causing the random fluctuations of the operating environment. The equipment is susceptible to progressive fault state under the E-factors stress during operation. If the abnormal operating environment is not diagnosed and maintained timely, the fault behavior is transferred and diffused among the mechanical components, and the progressive fault state also accumulates quickly. Eventually the function failure of the device would occur. Because of this, an adaptive maintenance model is proposed to diagnose and maintain progressive fault which is caused by environmental stress. It is shown in Figure 3. The adaptive maintenance model is composed of two parts. It is shown that the fluctuations of the manufacturing performance are caused by E-factors in part 1. And the monitoring and maintaining process are constructed in part 2.

The random fluctuations of the operating environment are considered during the system design process. E-factors are adjusted through the adaptive maintenance model based on the progressive fault state of the system. The method keeps the system in the normal operating environment.

Firstly, the system is running in the normal environment. According to the statistics, the stochastic dynamic environmental stresses are divided into several kinds such as temperature stress, humidity stress, vibration stress, and others.

Secondly, the stresses act on various components of the system causing a variety of physical and chemical reactions and affect the performance of the whole system to the progressive fault. If the progressive fault acts constantly on the system accumulating the fault state, that would lead to the function failure of the system. In the function failure process, the traditional fault diagnosis methods can be used for diagnosis and maintenance.

Thirdly, signal monitoring and recognition technology would be applied to the state of the system environment in the progressive fault process.

Fourthly, transcription factors and the array of state enzyme are constructed by the real-time operation of the system environment state and comapped to the expert system of the fault diagnosis established by the artificial intelligence methods. Environmental repair programs to the corresponding progressive fault states are obtained in the expert system.

Fifthly, the model uses transcription factors to activate or deactivate the components of the environmental repair programs and the state enzyme to adjust the trend and extent of the components. Then the closed-loop detection conditioning system is formed to repair the dynamic Efactors. And the progressive fault is removed by responding to the online environmental stress timely to maintain the normal operating environment of the system.

The specific steps are described as follows.

(1) Determine the system environment stress monitoring sites, $L$ :

$$
L=\left\{l_{i} \mid i=1,2, \ldots, n\right\} .
$$

(2) The environment data of the system is obtained in the normal operation from the historical data statistics, $T^{0}$ :

$$
T^{0}=\left\{t_{i}^{0} \mid i=1,2, \ldots, n\right\}
$$




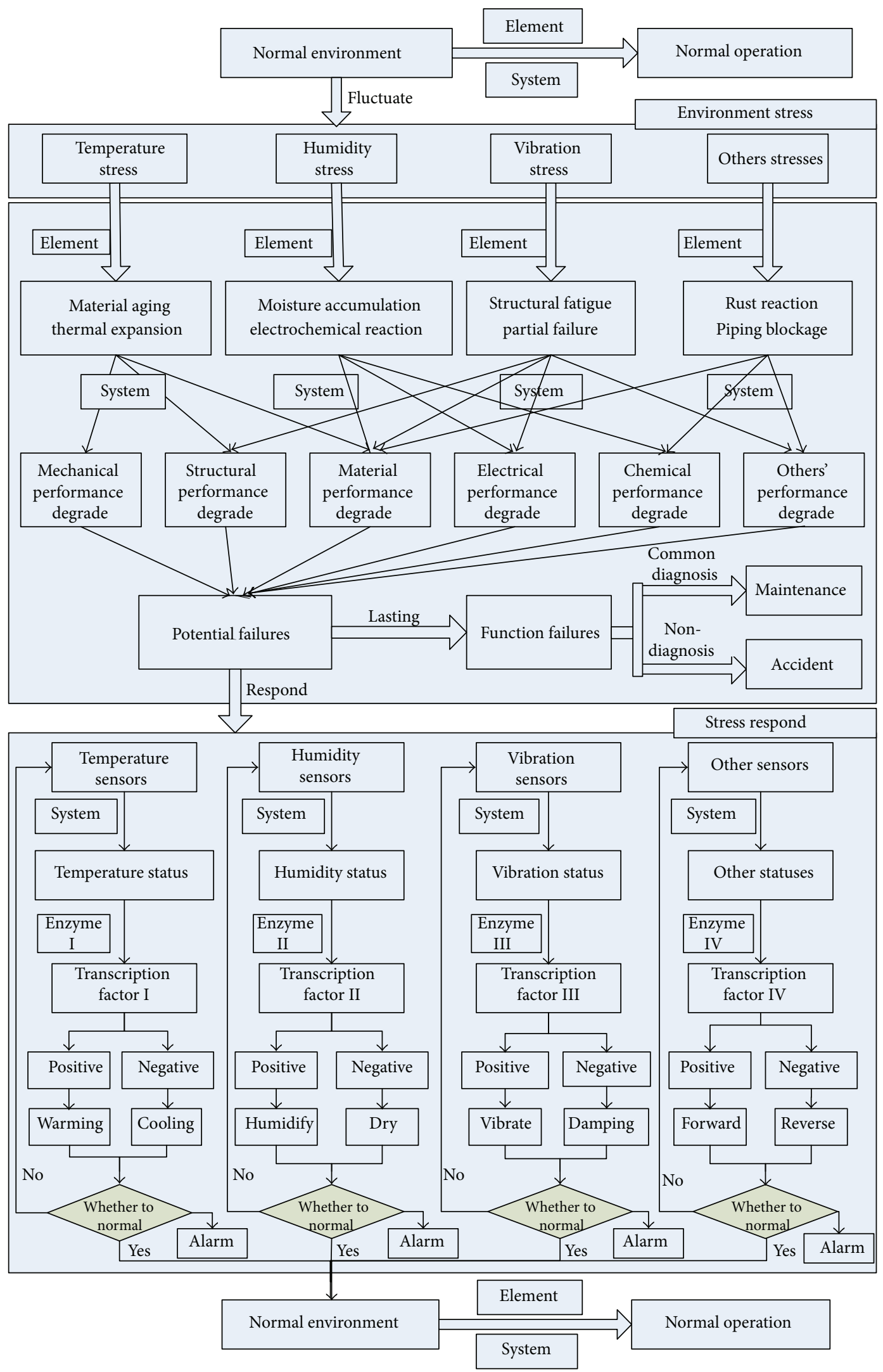

FIgURE 3: The adaptive maintenance model. 
(3) The range of the environment factors of the system is obtained during the normal operation through the analysis of the system performance, $T^{\prime}$ :

$$
T^{\prime}=\left\{\left|t_{i}^{\prime}\right| \mid i=1,2, \ldots, n\right\} .
$$

(4) The state enzyme array is constructed based on the structure and the control parameters of the components of the environmental repair programs, $E$.

The state enzyme $\left(e_{i j}\right)$ stands for the fluctuation extent of the failure/performance parameters of the same component of the system in different environments:

$E=\left\{e_{i j}=f\left(\Delta T_{i j}\right) \mid i=1,2, \ldots, n ; j=1,2, \ldots, m\right\}$.

(5) The system state array is constructed by real-time monitoring of the E-factors of the operation system, $T$ :

$$
T=\left\{t_{i j} \mid i=1,2, \ldots, n ; j=1,2, \ldots, m\right\} .
$$

(6) The environmental stress transcription factor array is calculated by monitoring the E-factor state data, $F$ :

$$
\begin{gathered}
F=\left\{f_{i j} \mid i=1,2, \ldots, n ; j=1,2, \ldots, m\right\}, \\
f_{i j}=\left\{\begin{array}{cc}
1 & \left|t_{i}^{\prime}\right|<\left|t_{i j}-t_{i}^{0}\right|, t_{i j}<t_{i}^{0} \\
0 & \left|t_{i}^{\prime}\right|>\left|t_{i j}-t_{i}^{0}\right| \\
-1 & \left|t_{i}^{\prime}\right|<\left|t_{i j}-t_{i}^{0}\right|, t_{i j}>t_{i}^{0}
\end{array} \quad(i=1,2, \ldots, n) .\right.
\end{gathered}
$$

Transcription factor is one of the concepts of genetics. The transcription factor array can be used in the field of fault diagnosis to determine the locations of system components which could be affected by the environmental stress and in the progressive fault state. The positive or negative of the matrix values shows out the trend of the progressive fault.

(7) By the transcription factor array $F$ and the state enzyme array $E$ comapping to the expert system of the fault diagnosis, obtain the comprehensive maintenance program for the environmental stress response $M$. While the transcription factor value $\left(f_{i j}\right)$ is 1 , it shows that the monitoring site $\left(l_{i}\right)$ is under the environmental stress and the response is positive, and while the transcription factor value $\left(f_{i j}\right)$ is 0 , it shows that the monitoring site $\left(l_{i}\right)$ is not under the environmental stress and it needs no response, and while the transcription factor value $\left(f_{i j}\right)$ is -1 , it shows that the monitoring site $\left(l_{i}\right)$ is under the environmental stress and the response is negative.

The repair effects of the environmental restoration program $(M)$ is determined by comparing the environment state data of the operating system (such as $T_{i}$ and $T_{i+1}$ ). If it is found out that the data and the trend do not match or exceed the regulatory range of the comprehensive maintenance $(M)$, then the alarm would be worn. Once in this kind of situation, the components of the system should be diagnosed or the system should be upgraded to prevent functional failure happening.
TABLE 1: Monitoring data of the booster expansion turbine.

\begin{tabular}{lcccc}
\hline Contents & \multicolumn{4}{c}{ Status } \\
& 1 & 2 & 3 & 4 \\
\hline $\begin{array}{l}\text { Outlet temperature } \\
\left({ }^{\circ} \mathrm{C}\right)\end{array}$ & -157.7 & -161.7 & -165.7 & -167.7 \\
$\begin{array}{l}\text { Oxygen content in } \\
\text { oxygen (\%) }\end{array}$ & 0.99953 & 0.99944 & 0.99933 & 0.99927 \\
$\begin{array}{l}\text { Nitrogen content } \\
\text { in nitrogen (\%) } \\
\begin{array}{l}\text { The ratio of oxygen } \\
\text { extraction (\%) }\end{array}\end{array}$ & 0.9998634 & 0.9998636 & 0.9998638 & 0.9998639 \\
\hline
\end{tabular}

\section{Sensitivity Analysis}

The air separation plant has the typical characteristics such as electrohydraulic system coupling, the complex spatial structure, and the high failure risk. The operation reliability and the product quality of the air separation plant are sensitive to environmental stresses such as temperature, humidity, vibration, and pressure. The temperature is one of the most important environmental stresses which the air separation plant must face. Its fluctuations affect the performance of the system.

The air separation process is mainly composed of a refrigerating system and rectification system, as shown in Figure 4. The simulation model includes the compressed air system, the precooling system, the purification system, the heat exchange system, the refrigeration system, and the distillation system. And there are parts of the air separation experimental setups shown in Figure 5 (the heat exchange system).

The precooling system of the air separation plant cools down by the circulating water. The temperature of the cooling water will decline with the drop of the atmospheric humidity and temperature and would enhance the cooling effect on the compressed air heat load; on the contrary, the temperature will rise with the rise of the atmospheric humidity and temperature and would decline the cooling effect.

The reduction of the cooling effect leads to the high temperature of the air before entering the purification system. And the high temperature air would affect the normal operation of the molecular sieve purification into the potential failure condition. Then the system production load is decreased, the productivity declines, and the power consumption increases.

$85 \%$ to $90 \%$ of the cooling capacity is produced by the turbine expander of the full low pressure air separation plant. The purified air passes through the turbine expander cooling to form the raw solution. The raw solution is separated into gas products by the distillation column.

The air separation processes are simulated and the outlet temperatures of the booster expansion turbine are adjusted in the simulation. Collect the changes of the purity of the oxygen product and the nitrogen product, the oxygen extraction rate, and other data. Parts of the collected data are shown in Table 1 and Figure 6. 


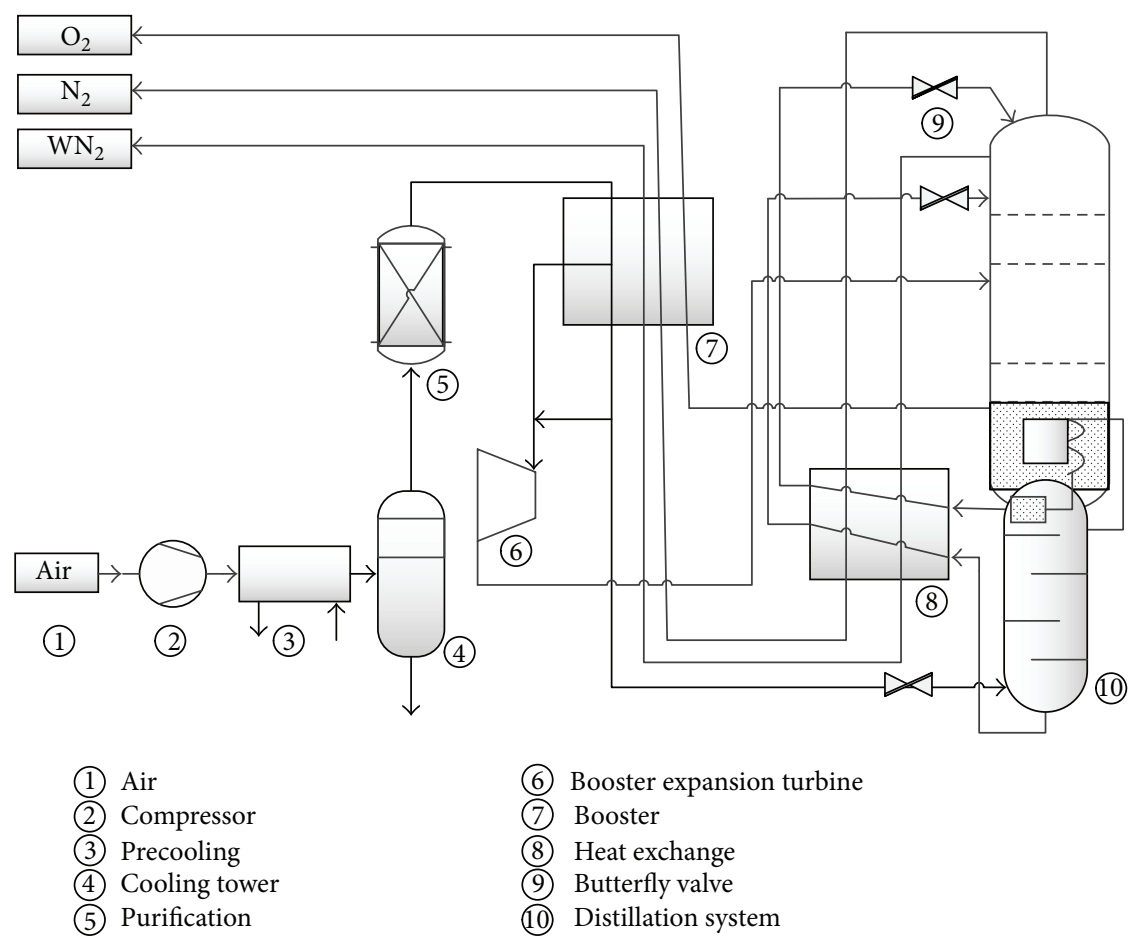

FIGURE 4: The simulation model of air separation process.

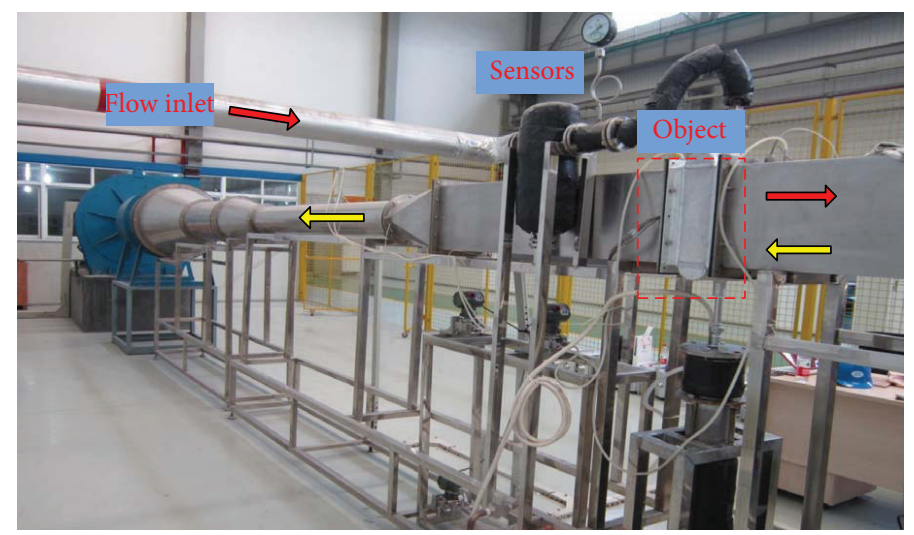

Figure 5: Parts of the air separation equipment.

It is shown directly in Figure 6. When the temperature of the booster turbo expander declines, the expansive air is blown into the feeding plate of the upper rectifying tower and its superheat drops down. That causes the vaporization of the reflux liquid in the rectifying section of the upper tower decrease. The liquid-gas ratio in the rectifying section is higher than at the original operational temperature. The oxygen fraction condenses fully from the vapor phases to the liquid phase because of the increase of the reflux liquid flow. The oxygen content of the vapor phase drops while the nitrogen content rises.

\section{Experiments}

A series of experiments were carried out to validate the proposed approach. The air separation process is simulated based on the data collected in the field on a certain type (7500/15000) of air separation plant in the normal operating environment. Construct the normal operating state $\left(S_{0}\right)$ of the simulated air separation according to the requirements of the air separation such as the convergence and the thermal coupling of the tower systems. And then monitor the Efactors such as inlet-outlet temperatures, pressures, and flows of the key equipments such as air compressors, precooling systems, purification systems, and the booster expansion turbine.

With reference to the system historical monitoring data, the process is simulated by adjusting E-factors on the air separation system. The simulation results are shown in Table 2.

For the operations, select the temperature stress which is one of the E-factors as the object from Table 2. Detect mainly 
TABLE 2: Statistics of the air separation process compared simulation.

\begin{tabular}{|c|c|c|c|c|c|c|c|c|c|}
\hline \multirow[t]{2}{*}{ Parameters } & \multirow[t]{2}{*}{$S$} & \multicolumn{4}{|c|}{$\begin{array}{l}\text { The operation in the stress state but } \\
\text { without the environmental stress response }\end{array}$} & \multicolumn{4}{|c|}{$\begin{array}{l}\text { The operation in the stress state and with } \\
\text { the environmental stress response }\end{array}$} \\
\hline & & $T_{1}$ & $T_{2}$ & $T_{3}$ & $T_{4}$ & $T_{5}$ & $T_{6}$ & $T_{7}$ & $T_{8}$ \\
\hline \multicolumn{10}{|c|}{ Air compressor } \\
\hline cp_in & $\mathrm{T}$ & 41.3 & 41.3 & 41.3 & 41.3 & 41.3 & 41.3 & 41.3 & 41.3 \\
\hline cp_out & $\mathrm{T}$ & 72.48 & 75.62 & 78.14 & 79.97 & 72.48 & 75.62 & 78.14 & 79.97 \\
\hline \multicolumn{10}{|c|}{ Precooling system } \\
\hline c_in & $\mathrm{T}$ & 72.57 & 75.47 & 77.98 & 80.51 & 72.57 & 75.47 & 77.98 & 80.51 \\
\hline C_out & $\mathrm{T}$ & 18.88 & 19.56 & 20.17 & 20.85 & 18.88 & 17.32 & 15.41 & 13.82 \\
\hline \multicolumn{10}{|c|}{ Purification system } \\
\hline $\mathrm{p}$ _in & $\mathrm{T}$ & 18.96 & 18.81 & 19.19 & 19.91 & 18.96 & 17.29 & 15.27 & 13.68 \\
\hline p_out & $\mathrm{T}$ & 29.87 & 31.56 & 34.24 & 37.11 & 29.87 & 25.75 & 21.29 & 17.14 \\
\hline \multicolumn{10}{|l|}{ Air booster } \\
\hline pb_in & $\mathrm{T}$ & 29.87 & 31.44 & 34.12 & 37.03 & 29.89 & 25.77 & 21.35 & 17.28 \\
\hline pb_out & $\mathrm{T}$ & 96.2 & 98.4 & 102.3 & 105.7 & 96.2 & 82.7 & 75.3 & 65.8 \\
\hline \multicolumn{10}{|c|}{ Booster expansion turbine } \\
\hline $\mathrm{e}$ in & $\mathrm{T}$ & -106.68 & -104.25 & -102.67 & -100.18 & -106.68 & -108.53 & -110.24 & -111.08 \\
\hline e_out & $\mathrm{T}$ & -158.2 & -157.5 & -155.7 & -153.5 & -158.2 & -158.9 & -159.8 & -161.4 \\
\hline \multicolumn{10}{|c|}{ Distillation tower } \\
\hline \multirow{3}{*}{ Flow } & $\mathrm{O}$ & 7395 & 7392 & 7388 & 7382 & 7395 & 7406 & 7419 & 7430 \\
\hline & $\mathrm{N}$ & 14547 & 14542 & 14539 & 14537 & 14547 & 14561 & 14572 & 14581 \\
\hline & WM & 11826 & 11829 & 11831 & 11837 & 11826 & 11821 & 11814 & 11809 \\
\hline \multirow[t]{2}{*}{ Purity } & $\mathrm{O}$ & 0.999287 & 0.999311 & 0.999338 & 0.999354 & 0.999287 & 0.999012 & 0.998772 & 0.998616 \\
\hline & $\mathrm{N}$ & 0.918654 & 0.918649 & 0.918642 & 0.918636 & 0.918654 & 0.918692 & 0.918706 & 0.918712 \\
\hline
\end{tabular}

the inlet and outlet temperatures of the air compressor, the precooling system, the purification system, and the booster expansion turbine and monitor the components of the gas products from the rectification tower. Then construct the array $(L)$ of the system monitoring locations:

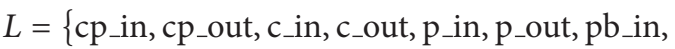

$$
\begin{aligned}
& \text { pb_out, e_in, e_out } \text {. }
\end{aligned}
$$

Construct the fluctuation range array $\left(T^{\prime}\right)$ to maintain the healthy state based on the environment parameters of the operation system.

Consider $T^{\prime}=\left\{\begin{array}{llllllllll}40 & 60 & 60 & 4 & 4 & 6 & 6 & 30 & 10 & 3\end{array}\right\}$. Construct the system state array $(T)$ based on the simulated data in Table 2.

The monitoring data $\left(T_{1} \sim T_{4}\right)$ in Table 2 are obtained by the timing simulation of the air separation process when the system is in the stress state $\left(S_{8}\right)$ but without the environmental stress response. It shows that the potential failure of the system accumulates constantly.

The monitoring data $\left(T_{5} \sim T_{8}\right)$ in Table 2 are obtained by the timing simulation of the air separation process when the system is in the stress state $\left(S_{8}\right)$ and the environmental stress response.
Then $T_{10,4}$ and $T_{10,4}^{\prime}$ can be obtained from Table 2:

$$
\begin{aligned}
& T_{10,4}=\left|\begin{array}{cccc}
41.30 & 41.30 & 41.31 & 41.31 \\
72.48 & 75.62 & 78.14 & 79.97 \\
72.57 & 75.47 & 77.98 & 80.51 \\
18.88 & 19.56 & 20.17 & 20.85 \\
18.96 & 18.81 & 19.19 & 19.91 \\
29.87 & 31.56 & 34.24 & 37.11 \\
29.87 & 31.44 & 34.12 & 37.03 \\
96.19 & 98.41 & 102.30 & 105.70 \\
-106.68 & -104.25 & -102.67 & -100.18 \\
-158.2 & -157.5 & -155.7 & -153.5
\end{array}\right|, \\
& T_{10,4}^{\prime}=\left|\begin{array}{cccc}
41.30 & 41.30 & 41.31 & 41.31 \\
72.48 & 75.62 & 78.14 & 79.97 \\
72.57 & 75.47 & 77.98 & 80.51 \\
18.88 & 17.32 & 15.41 & 13.82 \\
18.96 & 17.29 & 15.27 & 13.68 \\
29.87 & 25.75 & 21.29 & 17.14 \\
29.89 & 25.77 & 21.35 & 17.28 \\
96.19 & 82.71 & 75.34 & 65.80 \\
-106.68 & -108.53 & -110.24 & -111.08 \\
-158.18 & -158.91 & -159.83 & -161.42
\end{array}\right| .
\end{aligned}
$$

Locations of system components which are in the potential failure can be detected in the positive stresses by 


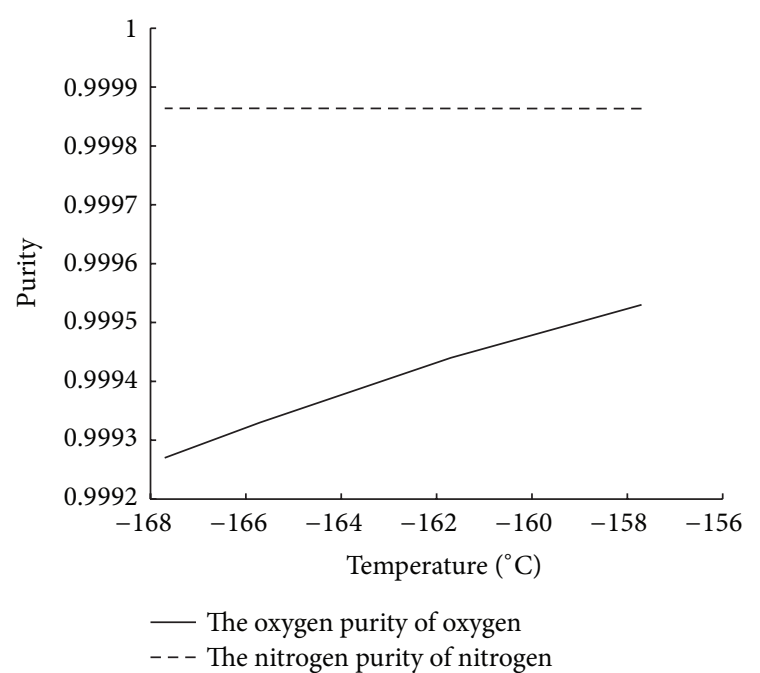

FIGURE 6: Diagrams of outlet temperatures of the booster expansion turbine and oxygen and nitrogen purity.

the transcription factor array $\left(F_{8}\right)$. Start a negative regulation scheme for the temperature stresses to cool down or cooling the ambient system environment, while the state enzyme array $\left(E_{8}\right)$ is obtained by comapping and calculating.

Make the most obvious state of the environmental stress $\left(S_{8}\right)$ as the state of the potential failure which is under the temperature stress in computing of the environmental stress response. According to formula 8, the transcription factor array $\left(F_{8}\right)$ can be obtained as follows:

$$
\begin{aligned}
& F_{8}=\left\{\begin{array}{cccc}
26.8<40 & & \longrightarrow 0 \\
36<60 & & \longrightarrow 0 \\
36<60 & & \longrightarrow & 0 \\
5.98>4 & 12.2<18.18 & \longrightarrow & -1 \\
6.06>4 & 12.2<18.26 & \longrightarrow & -1 \\
14.07>6 & 15.8<29.87 & \longrightarrow & -1 \\
14.07>6 & 15.8<29.87 & \longrightarrow & -1 \\
37.12>30 & 59.08<96.2 & \longrightarrow & -1 \\
6.93<10 & & \longrightarrow 0 \\
6.9>3 & -165.1<-158.2 & \longrightarrow & -1
\end{array}\right. \\
& F_{8}=\{0,0,0,-1,-1,-1,-1,-1,0,-1\}, \\
& E_{8}=\left\{e_{i j}=f\left(\Delta T_{i j}\right) \mid i=1,2, \ldots, n ; j=1,2, \ldots, m\right\} \\
& =\{0,0,0,1.49,1.52,2.35,2.35,1.24,0,2.3\}
\end{aligned}
$$

Cool down the components which are under the potential failure and the ambient environment by operating the comprehensive maintenance program $\left(M_{8}\right)$ to adjust the Efactors.

The comparisons of the air separation process simulation between those without (solid line) and those with (dotted line) the environmental stress response are shown in Figures 7 and 8 . The outlet temperatures of the precooling system, the purification system, and the air compressor are shown in Figure 7. The inlet-outlet temperatures of the booster expansion turbine are shown in Figure 8.

It can be seen by the comparisons that it is effective to take the environmental stress response on the operational

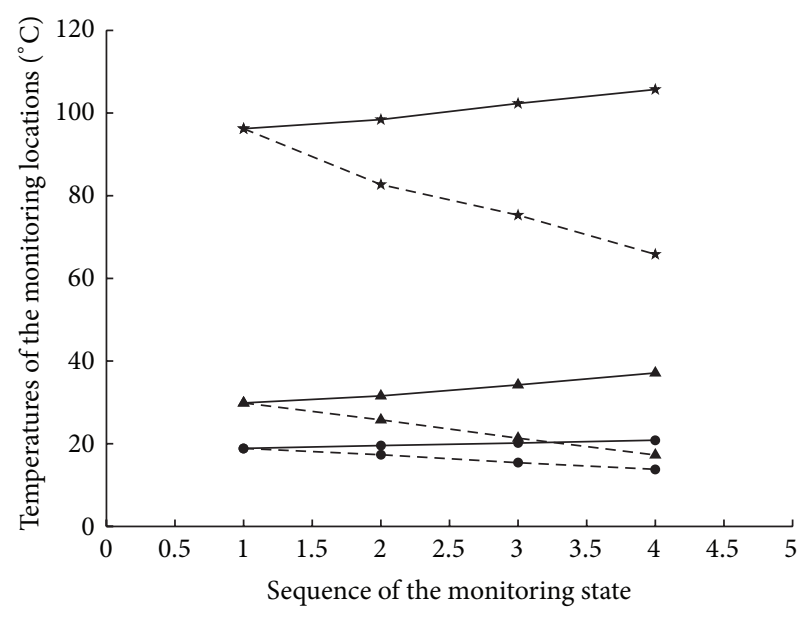

$\rightarrow \quad$ c_out: outlet temperature of precooling system

- - c_out: outlet temperature with environmental stress response

—_ p_out: outlet temperature of purification system

- $\_$- p_out: outlet temperature with environmental stress response

$\star$ pb_out: outlet temperature of air booster

$-\star-$ pb_out: outlet temperature with environmental stress response

Figure 7: Contrast diagram of the running temperatures of the components.

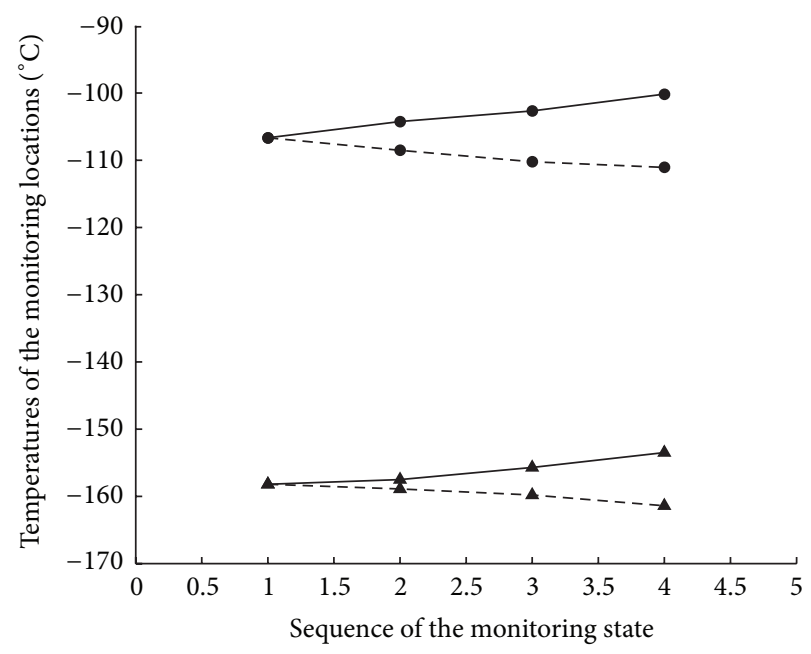

\footnotetext{
$\longrightarrow$ e_in: inlet temperature of the booster expansion turbine - - e_in: inlet temperature with environmental stress response $\_$e_out: outlet temperature of the booster expansion turbine - $\_$- e_out: outlet temperature with environmental stress response
}

FIgURE 8: Contrast diagram of the inlet and outlet temperatures of the booster expansion turbine.

phase of the air separation system as shown in Table 3. The reducing of the temperature means low power consumption of the manufacturing system and the increasing of production means higher benefits. Also the normal operating environment would extend the service life of the system.

\section{Conclusion}

We presented an adaptive maintenance model to repair the process environment which caused progressive faults in 
TABLE 3: Analysis of the effect of the adaptive maintenance model.

\begin{tabular}{lcccc}
\hline \multirow{2}{*}{ Locations } & \multicolumn{4}{c}{ Status } \\
& $T_{4}\left({ }^{\circ} \mathrm{C}\right)$ & $T_{8}\left({ }^{\circ} \mathrm{C}\right)$ & $\Delta T\left({ }^{\circ} \mathrm{C}\right)$ & $\Delta \%$ \\
\hline c_out & 20.85 & 13.82 & -7.03 & -33.72 \\
p_out & 37.11 & 17.14 & -19.97 & -53.81 \\
pb_out & 105.7 & 65.8 & -39.9 & -37.75 \\
e_in & -100.18 & -111.08 & -10.9 & -10.88 \\
e_out & -153.5 & -161.4 & -7.9 & -5.15 \\
F_O & 7382 & 7430 & 48 & +0.65 \\
F_N & 14537 & 14581 & 44 & +0.30 \\
\hline
\end{tabular}

the air separation plant system. This maintenance approach includes the following. (1) The diagnostic model monitors the environmental states of the plants and also compares the inputs/outputs and presettings to detect faults. (2) The mapping structure is constructed with the I/O environmental states and behaviors of carriers, while the state enzyme and the transcription factor array are calculated through the expert system. (3) The comprehensive maintenance program is obtained by the comapping of the state enzyme and the transcription factor array for the environmental stress response.

For the future research, we suggest to optimize the deployment of the sensors for the model. Through preselection of sensor locations, it may improve the detection of the system with optimal cost and sensor configuration.

\section{Conflict of Interests}

The authors declare that they have no conflict of interests regarding the publication of this paper.

\section{Acknowledgments}

This work was supported by the National Natural Science Foundation of China (No. 51322506 and 51175456), Zhejiang Provincial Natural Science Foundation of China (No. LR14E050003), the Fundamental Research Funds for the Central Universities, Innovation Foundation of the State Key Laboratory of Fluid Power Transmission and Control, and Zhejiang University K.P. Chao's High Technology Development Foundation. Sincere appreciation is extended to the reviewers of this paper for their helpful comments.

\section{References}

[1] R. V. Beard, Failure Accommodation in Linear Systems through Self-Reorganization, MIT, Cambridge, Mass, USA, 1971.

[2] M. Demetgul, "Fault diagnosis on production systems with support vector machine and decision trees algorithms," The International Journal of Advanced Manufacturing Technology, vol. 67, no. 9-12, pp. 2183-2194, 2013.

[3] J. Yang, Y. Zhang, and Y. Zhu, "Intelligent fault diagnosis of rolling element bearing based on SVMs and fractal dimension," Mechanical Systems and Signal Processing, vol. 21, no. 5, pp. 2012-2024, 2007.
[4] S. F. Yuan and F. L. Chu, "Support vector machines-based fault diagnosis for turbo-pump rotor," Mechanical Systems and Signal Processing, vol. 20, no. 4, pp. 939-952, 2006.

[5] A. Widodo and B. Yang, "Support vector machine in machine condition monitoring and fault diagnosis," Mechanical Systems and Signal Processing, vol. 21, no. 6, pp. 2560-2574, 2007.

[6] A. Widodo, B. Yang, and T. Han, "Combination of independent component analysis and support vector machines for intelligent faults diagnosis of induction motors," Expert Systems with Applications, vol. 32, no. 2, pp. 299-312, 2007.

[7] Y. Yang, D. Yu, and J. Cheng, "A fault diagnosis approach for roller bearing based on IMF envelope spectrum and SVM," Measurement: Journal of the International Measurement Confederation, vol. 40, no. 9-10, pp. 943-950, 2007.

[8] P. Stepanic, I. V. Latinovic, and Z. Djurovic, "A new approach to detection of defects in rolling element bearings based on statistical pattern recognition," International Journal of Advanced Manufacturing Technology, vol. 45, no. 1-2, pp. 91-100, 2009.

[9] F. Pan, S. R. Qin, and L. Bo, "Development of diagnosis system for rolling bearings faults based on virtual instrument technology," Journal of Physics: Conference Series, vol. 48, article 467, 2006.

[10] C. Angeli, "An online expert system for fault diagnosis in hydraulic systems," Expert Systems, vol. 16, no. 2, pp. 115-120, 1999.

[11] C. Angeli and A. Chatzinikolaou, "On-line fault detection techniques for technical systems: a survey," International Journal of Computer Science \& Applications, vol. 1, no. 1, pp. 12-30, 2004.

[12] B. Samanta and K. R. Al-Balushi, "Artificial neural network based fault diagnostics of rolling element bearings using timedomain features," Mechanical Systems and Signal Processing, vol. 17, no. 2, pp. 317-328, 2003.

[13] T. Lindh, On the condition monitoring of induction machines [Ph.D. thesis], Lappeenranta University of Technology, 2003.

[14] I. B. Gertsbakh, Models of Preventive Maintenance, North-Holland Publishing, Oxford, UK, 1977.

[15] H. Löfsten, "Management of industrial maintenance-economic evaluation of maintenance policies," International Journal of Operations and Production Management, vol. 19, no. 7, pp. 716737, 1999.

[16] J. S. Usher, A. H. Kamal, and W. H. Syed, "Cost optimal preventive maintenance and replacement scheduling," IIE Transactions, vol. 30, no. 12, pp. 1121-1128, 1998.

[17] L. Pintelon and G. Waeyenbergh, "A practical approach to maintenance modelling," in Flexible Automation and Intelligent Manufacturing, J. Ashayeri, W. G. Sullivan, and M. M. Ahmad, Eds., pp. 1109-1119, Begell House, New York, NY, USA, 1999.

[18] G. Waeyenbergh and L. Pintelon, "A framework for maintenance concept development," International Journal of Production Economics, vol. 77, no. 3, pp. 299-313, 2002.

[19] H. Wang, "A survey of maintenance policies of deteriorating systems," European Journal of Operational Research, vol. 139, no. 3, pp. 469-489, 2002.

[20] M. Wiseman, “Optimizing condition based maintenance," Plant Engineering and Maintenance, vol. 23, no. 6, pp. 57-71, 2001.

[21] Y. Liao, G. Lang, and L. Qu, "Precession trend analysis and balancing strategy for rotors with multi-fault," Journal of Mechanical Engineering, vol. 45, no. 8, pp. 45-51, 2009.

[22] L. Dieulle, C. Bérenguer, A. Grall, and M. Roussignol, "Sequential condition-based maintenance scheduling for a deteriorating system," European Journal of Operational Research, vol. 150, no. 2, pp. 451-461, 2003. 
[23] M. Kearney, J. Marshall, and B. Newman, "Comparison of reliability enhancement tests for electronic equipment," in Proceedings of the Reliability and Maintainability Symposium, pp. 435440, Singapore, January 2003.

[24] R. Ahmad and S. Kamaruddin, "An overview of time-based and condition-based maintenance in industrial application," Computers and Industrial Engineering, vol. 63, no. 1, pp. 135-149, 2012.

[25] R. D. Brillhart, D. L. Hunt, and H. Chimerine, "Multiple input excitation methods for aircraft ground vibration testing," Sound and Vibration, vol. 27, no. 1, pp. 77-85, 1993.

[26] Y. Umeda, T. Takeda Tomiyama et al., "Function behavior and structure," Application of Artificial Intelligence in Engineering, vol. 10, no. 4, pp. 177-193, 1990. 


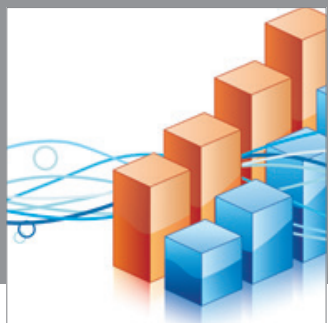

Advances in

Operations Research

mansans

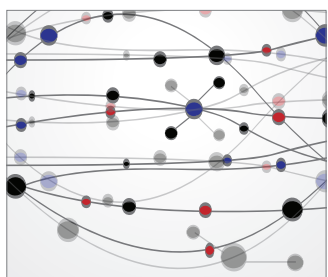

The Scientific World Journal
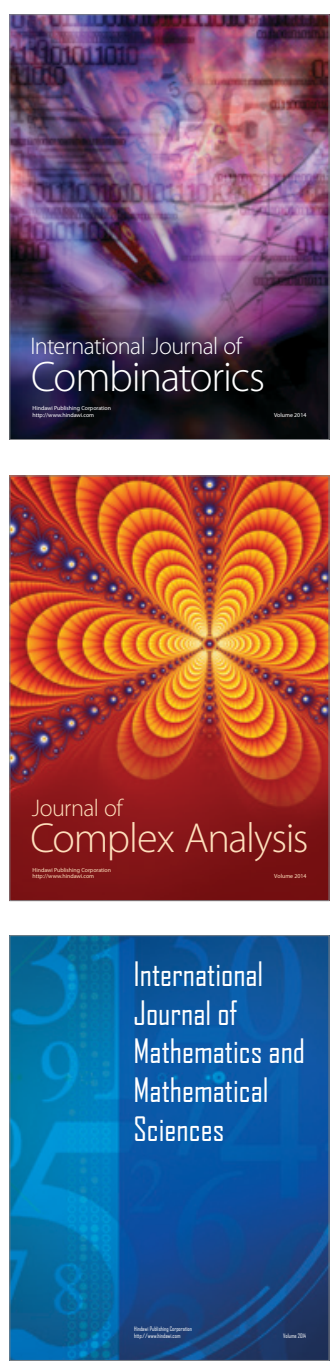
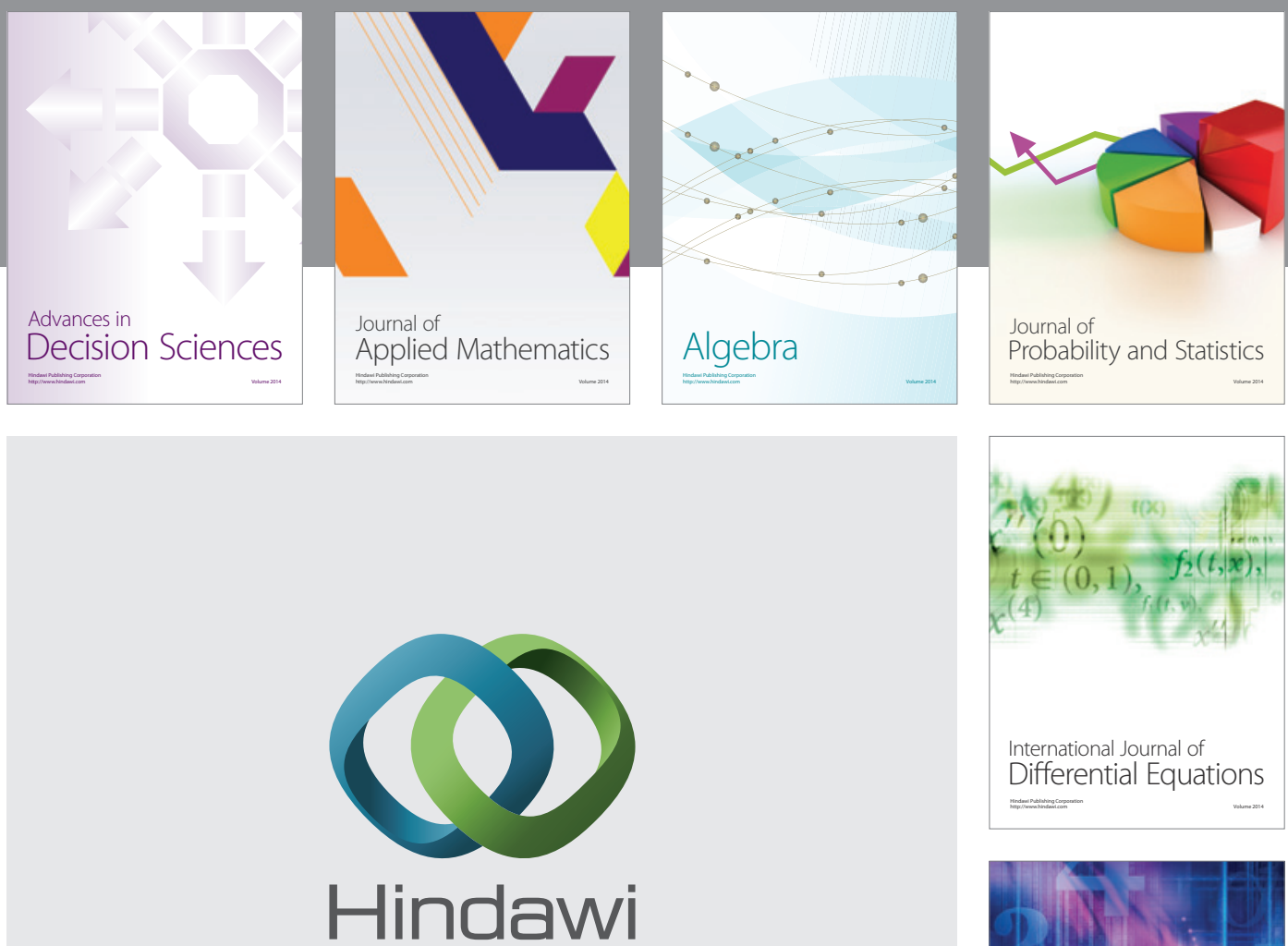

Submit your manuscripts at http://www.hindawi.com
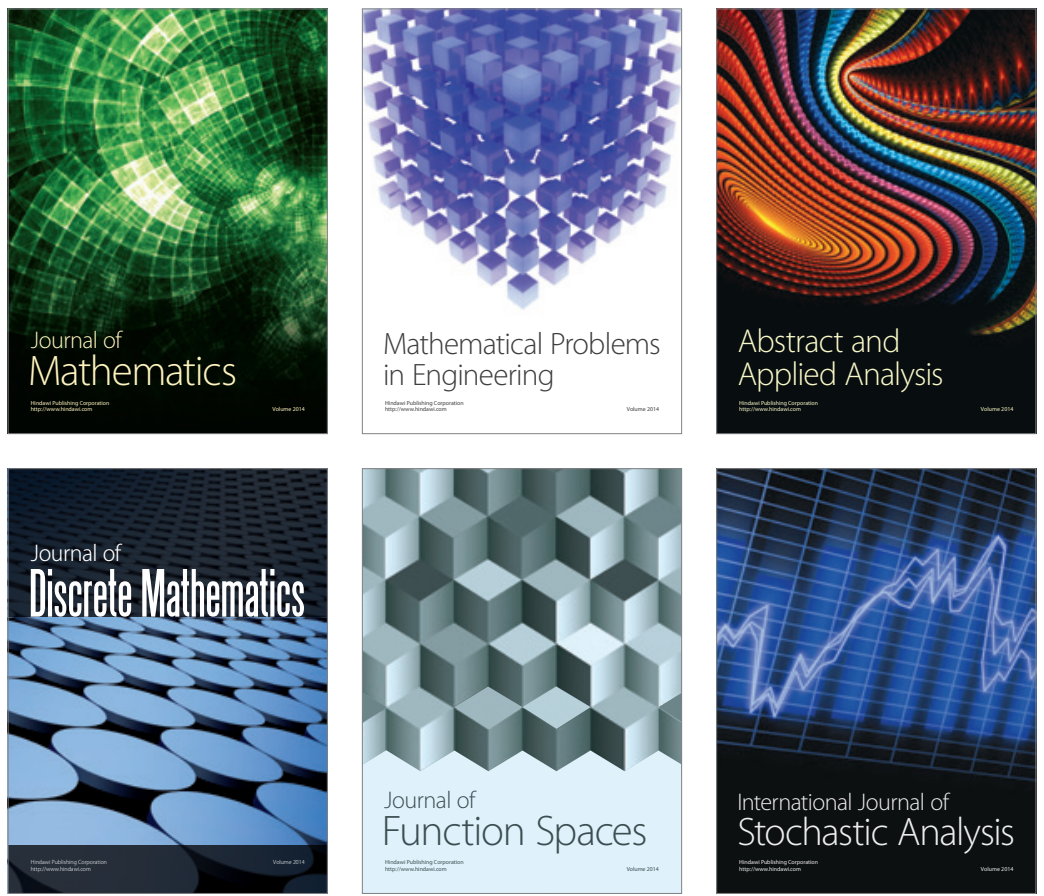

Journal of

Function Spaces

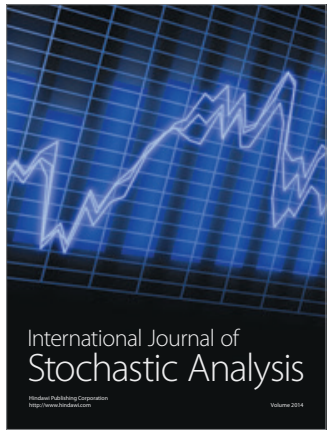

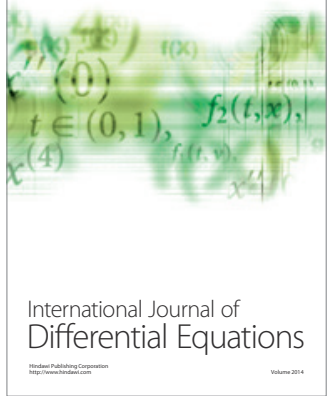
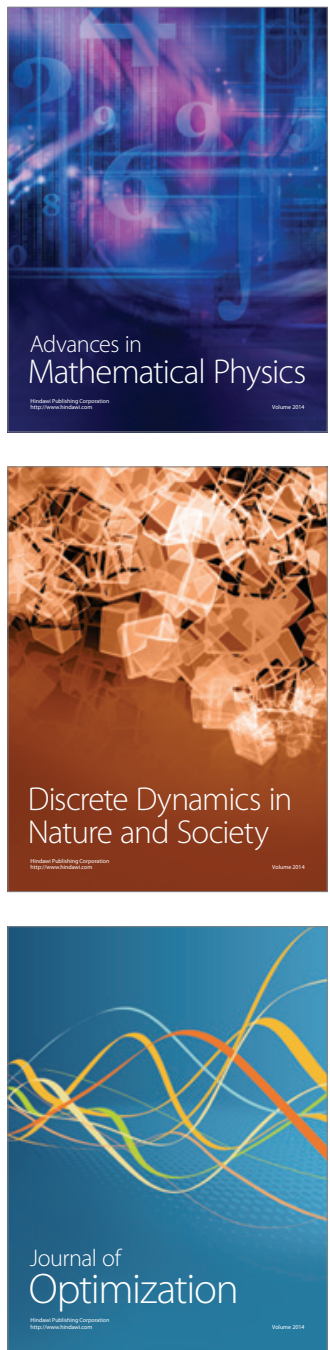